Brain, Behavior and Evolution
Brain Behav Evol 2011;77:33-44

DOI: $\underline{10.1159 / 000322729}$
Received: June 1, 2010

Returned for revision: July 14, 2010

Accepted after revision: November 15, 2010

Published online: January 11, 2011

\title{
Gorilla and Orangutan Brains Conform to the Primate Cellular Scaling Rules: Implications for Human Evolution
}

\author{
Suzana Herculano-Houzel ${ }^{\mathrm{a}}$ Jon H. Kaas ${ }^{\mathrm{b}}$ \\ a Instituto de Ciências Biomédicas, Universidade Federal do Rio de Janeiro, and Instituto Nacional de Neurociência \\ Translacional, Rio de Janeiro, Brazil; ${ }^{\text {b }}$ Department of Psychology, Vanderbilt University, Nashville, Tenn., USA
}

\section{Key Words}

Allometry $\cdot$ Brain size $\cdot$ Great apes $\cdot$ Human •

Evolution, human $\cdot$ Neurons, number

\begin{abstract}
Gorillas and orangutans are primates at least as large as humans, but their brains amount to about one third of the size of the human brain. This discrepancy has been used as evidence that the human brain is about 3 times larger than it should be for a primate species of its body size. In contrast to the view that the human brain is special in its size, we have suggested that it is the great apes that might have evolved bodies that are unusually large, on the basis of our recent finding that the cellular composition of the human brain matches that expected for a primate brain of its size, making the human brain a linearly scaled-up primate brain in its number of cells. To investigate whether the brain of great apes also conforms to the primate cellular scaling rules identified previously, we determine the numbers of neuronal and other cells that compose the orangutan and gorilla cerebella, use these numbers to calculate the size of the brain and of the cerebral cortex expected for these species, and show that these match the sizes described in the literature. Our
\end{abstract}

results suggest that the brains of great apes also scale linearly in their numbers of neurons like other primate brains, including humans. The conformity of great apes and humans to the linear cellular scaling rules that apply to other primates that diverged earlier in primate evolution indicates that prehistoric Homo species as well as other hominins must have had brains that conformed to the same scaling rules, irrespective of their body size. We then used those scaling rules and published estimated brain volumes for various hominin species to predict the numbers of neurons that composed their brains. We predict that Homo heidelbergensis and Homo neanderthalensis had brains with approximately 80 billion neurons, within the range of variation found in modern Homo sapiens. We propose that while the cellular scaling rules that apply to the primate brain have remained stable in hominin evolution (since they apply to simians, great apes and modern humans alike), the Colobinae and Pongidae lineages favored marked increases in body size rather than brain size from the common ancestor with the Homo lineage, while the Homo lineage seems to have favored a large brain instead of a large body, possibly due to the metabolic limitations to having both.

Copyright $\odot 2011$ S. Karger AG, Basel

Suzana Herculano-Houzel

Instituto de Ciências Biomédicas, UFRJ

Rua Carlos Chagas Filho 337

Ilha do Fundão, Rio de Janeiro, RJ 21941-920 (Brazil)

Tel. +55 212562 6390, Fax +55 212290 0587, E-Mail suzanahh@ gmail.com 


\section{Introduction}

Gorillas and orangutans are primates that overlap with or exceed humans in body size, but their brains amount to about one third of the size of the human brain [Marino, 1998]. If body size is considered a predictor of brain size, the comparison of how these 2 variables scale across species leads to the conclusion that the human brain is up to 7 times larger than expected for a mammal of its body size [Jerison, 1973], or more than 3 times larger than expected for a primate of its body size [Marino, 1998]. Combined with other data such as relative size of the cerebral cortex and white matter, these findings have been grounds for considering the human brain as an outlier, an exception to the rules that apply to how brain size scales in nature [Marino, 1998; Rilling, 2006; Gazzaniga, 2008].

However, when body size is not taken into consideration, we have found that the human brain, with 86 billion neurons and 85 billion non-neuronal cells, has a cellular composition that matches what would be expected for a generic primate of its brain size [Azevedo et al., 2009]. Given the linear cellular scaling rules that apply to the cerebral cortex, cerebellum and the remaining structures of primate brains [Herculano-Houzel et al., 2007], we concluded that the human brain is a linearly scaled-up primate brain in its number of cells. Moreover, in comparison to how brain and body size vary in a sample of 6 New- and Old-World primates, we have shown that the human brain actually has the mass and number of cells expected for a primate of about $70 \mathrm{~kg}$ [Azevedo et al., 2009]. This is strikingly different to previous reports that the human brain is larger than expected for the human body size [Jerison, 1973; Marino, 1998], a discrepancy that can be explained by the finding that the exponent that describes the brain-body scaling relationship is highly dependent on the species sampled, while the neuronal scaling rules that apply to primate brains are insensitive to the choice of species [Gabi et al., 2010]. Body mass, therefore, is a poor predictor of brain mass in primates.

The finding that the same neuronal scaling rules apply to the brains of non-hominoid primates that diverged from our common ancestor over 40 million years ago as well as to the more recent human species indicates that these rules are also shared by the brains of great apes and hominin species that diverged from the common ancestral lineage at intermediate times of 14 to $<1$ million years ago. Here we examine this possibility by analyzing the numbers of neuronal and other cells that compose the cerebellum of 1 gorilla and 3 orangutans to determine if they match the numbers predicted for primates, in contrast to hypothetical rodents of similar-sized cerebella as an outgroup for comparison. Based on the number of cells found in the gorilla and orangutan cerebella, we also determine the predicted size of the whole brain and cerebral cortex for primates and compare them to values described in the literature. Finally, we use the cellular scaling rules found to apply to non-human primates, humans and great apes to infer the cellular composition of prehistoric hominin species, and propose a reappraisal of the concept of encephalization under the light of how brain and body size have varied in the course of primate evolution.

\section{Materials and Methods}

Whole cerebella from 3 adult orangutans (Pongo sp., 1 female, 2 of unknown sex) and 1 gorilla (Gorilla gorilla, sex unknown) were donated by Dr. Margarete Tigges of the Yerkes Regional Research Center in Atlanta, Ga., USA. These brain parts were obtained in 1997 after they had been stored for some years in 4\% paraformaldehyde, and were maintained in fixative for over 10 years until processed in 2008. The left cerebellar hemisphere of the gorilla and 1 orangutan and the right cerebellar hemisphere of 2 orangutans were separated by cutting along the vermis, blotted dry, weighed, and processed with the isotropic fractionator [Herculano-Houzel and Lent, 2005].

Briefly, each cerebellar hemisphere was diced, then fully dissociated in a $0.1 \%$ Triton X-100 solution in $40 \mathrm{~mm}$ sodium citrate in glass homogenizers. The resulting nuclear suspension was stained with DAPI (diluted 50 times from a stock solution of 10 $\mathrm{mg} / \mathrm{l}$ ), had its volume adjusted with phosphate-buffered saline to a known value (typically $1,000 \mathrm{ml}$ ), and was made isotropic by thorough agitation by inversion so as not to form bubbles. The density of DAPI-stained nuclei in the suspensions from each cerebellar hemisphere was determined by counting at least 4 samples of each suspension in a hemocytometer under a fluorescence microscope (Zeiss Axioplan, Jena, Germany), which yields a coefficient of variation of typically less than $10 \%$ across measurements of the same tissue. The total number of nuclei in the suspension, and hence the total number of cells in the whole cerebellum, was obtained by multiplying the density of nuclei by the suspension volume, and then multiplying the result by 2 . Since granular cells amount to the vast majority of the neuronal population in the cerebellum, and because immunocytochemical methods are not applicable to tissue that has been fixed for over 10 years, we estimated the number of neurons in the great ape cerebella by determining the percentage of nuclei of granular morphology as well as the percentage of Purkinje cell nuclei in samples of over 40,000 nuclei from each cerebellar hemisphere (fig. 1).

The average number of all cells and of granular cells in the cerebellum of each species was then used to calculate the expected mass and numbers of neuronal and other cells of the whole brain and of its major divisions, as well as body mass, using equations derived from average data for each species published for 6 

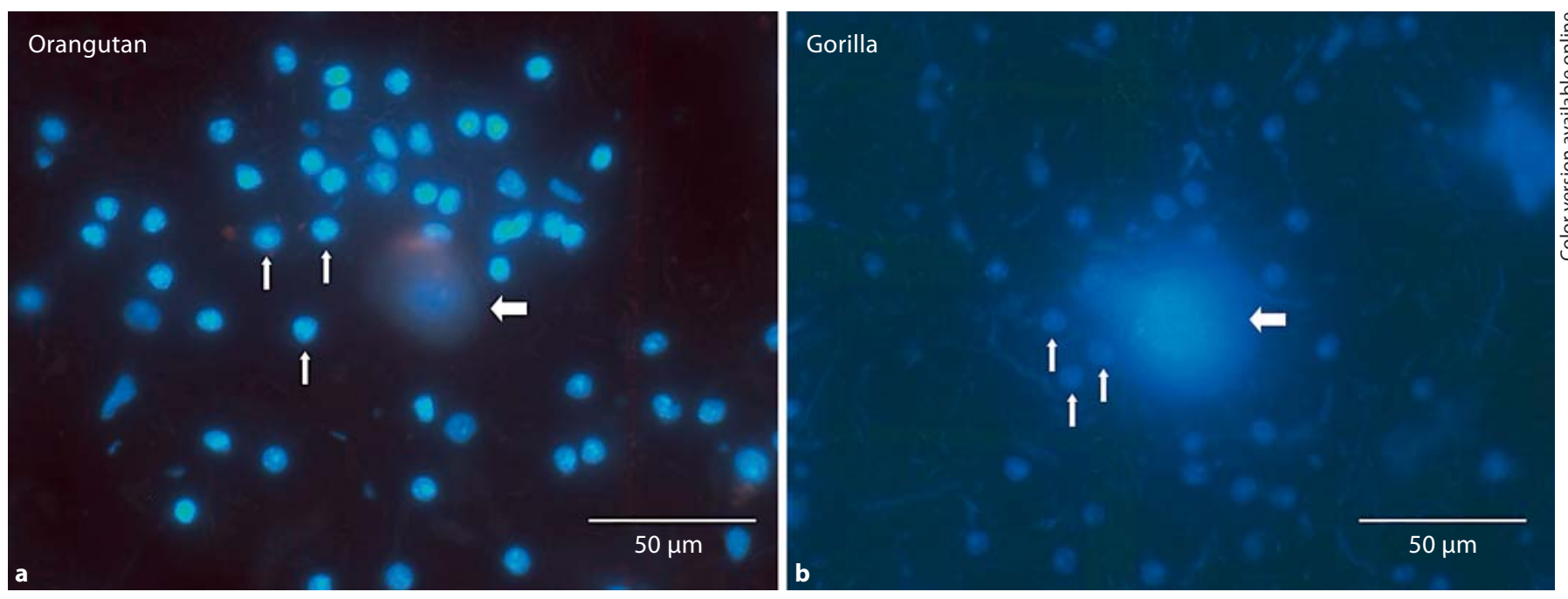

Fig. 1. DAPI-stained granule and Purkinje cell nuclei in orangutan (a) and gorilla (b) cerebella can be distinguished by morphology. Horizontal arrows point to Purkinje cell nuclei; vertical arrows point to a few of several granule cell nuclei visible in the fields.

Table 1. Equations determining the expected mass and numbers of cells in the whole brain, cerebral cortex, cerebellum and rest of brain from whole brain mass in primates

\begin{tabular}{llll}
\hline & Mass & Number of neurons & Number of non-neurons \\
\hline Whole brain & & $\mathrm{N}_{\mathrm{BR}}=109,239,790.169 \times \mathrm{M}_{\mathrm{BR}}^{0.923}$ & $\mathrm{NN}_{\mathrm{BR}}=69,199,591.082 \times \mathrm{M}_{\mathrm{BR}}{ }^{1.011}$ \\
Cerebral cortex & $\mathrm{M}_{\mathrm{CX}}=0.564 \times \mathrm{M}_{\mathrm{BR}}{ }^{1.070}$ & $\mathrm{~N}_{\mathrm{CX}}=37,813,551.018 \times \mathrm{M}_{\mathrm{BR}}^{0.891}$ & $\mathrm{NN}_{\mathrm{CX}}=35,281,258.745 \times \mathrm{M}_{\mathrm{BR}} 1.104$ \\
Cerebellum & $\mathrm{M}_{\mathrm{CB}}=0.128 \times \mathrm{M}_{\mathrm{BR}}{ }^{0.937}$ & $\mathrm{~N}_{\mathrm{CB}}=69,640,042.656 \times \mathrm{M}_{\mathrm{BR}}{ }^{0.936}$ & $\mathrm{NN}_{\mathrm{CB}}=5,851,284.369 \times \mathrm{M}_{\mathrm{BR}}{ }^{1.039}$ \\
Rest of brain & $\mathrm{M}_{\mathrm{ROB}}=0.348 \times \mathrm{M}_{\mathrm{BR}}{ }^{0.769}$ & $\mathrm{~N}_{\mathrm{ROB}}=7,374,107.052 \times \mathrm{M}_{\mathrm{BR}}{ }^{0.604}$ & $\mathrm{NN}_{\mathrm{ROB}}=30,691,201.606 \times \mathrm{M}_{\mathrm{BR}}{ }^{0.738}$ \\
\hline
\end{tabular}

Equations calculated from data for 6 non-human primate species in Herculano-Houzel et al. [2007]. All values p < 0.01.

primate species [Herculano-Houzel et al., 2007], and for 6 rodent species [Herculano-Houzel et al., 2006] for comparison. These expected values were then compared to values described in the literature [Stephan et al., 1981; Frahm et al., 1982; Marino, 1998; Semendeferi and Damasio, 2000; de Sousa and Woods, 2007]; where necessary, values reported in the literature as $\mathrm{cm}^{3}$ were multiplied by a brain tissue density of $1.06 \mathrm{~g} / \mathrm{cm}^{3}$ to yield the equivalent structure mass in grams for comparison. The expected mass and numbers of neuronal and other cells for great apes were compared to expected and observed values for the human brain as well as other primates, using numbers published recently [Herculano-Houzel et al., 2006; Azevedo et al., 2009]. Phylogenetic independent contrasts were calculated to examine the scaling of the primate cerebellum as a function of its numbers of cells or neurons in the dataset of 9 primate species, including orangutans, gorillas and humans, while controlling for effects of phylogenetic relatedness in the dataset [Felsenstein, 1985]. Standardized independent contrasts were calculated using the PDAP:PDTREE module of Mesquite software, version 2.7 [Maddison and Maddison, 2005]. Contrasts were calculated from log-transformed data. Phylogenetic relationships are based on Purvis [1995]. Branch lengths were transformed according to the method of $\mathrm{Pa}-$ gel [1992], which assigns all branch lengths to 1 with the constraint that tips are contemporaneous. The reported values for the linear regressions of independent contrasts on log-transformed data are reduced major axis (RMA) slope and p value.

Finally, we predicted the numbers of neuronal and other cells in hominin brains based on their putative mass described by de Sousa and Woods [2007]. For that end, we used average values available for 6 primate species [Herculano-Houzel et al., 2007] to calculate the equations that describe the mass of the cerebral cortex, cerebellum, and rest of brain as a function of total brain mass, and that relate the numbers of neurons and other cells in each of these structures and in the whole brain to total brain mass (table 1). 
Table 2. Deviation from expected cellular composition of the cerebellum

\begin{tabular}{|c|c|c|c|c|c|c|}
\hline \multirow[t]{2}{*}{ Species and cerebellar mass } & \multicolumn{3}{|c|}{$\begin{array}{l}\text { Number of cells expected from primate } \\
\text { cerebellar mass, } C_{C b}=619,105,857.039 \times M_{C b}{ }^{0.987}\end{array}$} & \multicolumn{3}{|c|}{$\begin{array}{l}\text { Number of cells expected from rodent } \\
\text { cerebellar mass, } \mathrm{C}_{\mathrm{Cb}}=386,335,032 \times \mathrm{M}_{\mathrm{Cb}} 0.766\end{array}$} \\
\hline & expected & observed & deviation $^{\mathrm{a}}$ & expected & observed & deviation $^{\mathrm{a}}$ \\
\hline Callithrix jacchus (0.73 g) & $453.80 \times 10^{6}$ & $410.86 \times 10^{6}$ & $-9.5 \%$ & $303.58 \times 10^{6}$ & $410.86 \times 10^{6}$ & $35.3 \%$ \\
\hline Otolemur garnettii $(1.20 \mathrm{~g})$ & $738.73 \times 10^{6}$ & $809.46 \times 10^{6}$ & $9.6 \%$ & $443.10 \times 10^{6}$ & $809.46 \times 10^{6}$ & $82.7 \%$ \\
\hline Aotus trivirgatus (1.73 g) & $1.06 \times 10^{9}$ & $1.18 \times 10^{9}$ & $10.8 \%$ & $588.42 \times 10^{6}$ & $1.18 \times 10^{9}$ & $100.5 \%$ \\
\hline Saimiri sciureus (4.30 g) & $2.61 \times 10^{9}$ & $1.95 \times 10^{9}$ & $-25.3 \%$ & $1.18 \times 10^{9}$ & $1.95 \times 10^{9}$ & $65.1 \%$ \\
\hline Cebus apella (4.60 g) & $2.79 \times 10^{9}$ & $2.74 \times 10^{9}$ & $-1.9 \%$ & $1.24 \times 10^{9}$ & $2.74 \times 10^{9}$ & $120.4 \%$ \\
\hline Macaca mulatta (7.69 g) & $4.64 \times 10^{9}$ & $5.48 \times 10^{9}$ & $18.1 \%$ & $1.84 \times 10^{9}$ & $5.48 \times 10^{9}$ & $197.2 \%$ \\
\hline Pongo pygmaeus (35.06 g) & $20.69 \times 10^{9}$ & $28.5 \times 10^{9}$ & $31.9 \%$ & $5.88 \times 10^{9}$ & $28.5 \times 10^{9}$ & $384.3 \%$ \\
\hline Gorilla gorilla $(37.56 \mathrm{~g})$ & $22.21 \times 10^{9}$ & $29.3 \times 10^{9}$ & $37.7 \%$ & $6.22 \times 10^{9}$ & $29.3 \times 10^{9}$ & $371.3 \%$ \\
\hline Homo sapiens (154.02 g) & $89.31 \times 10^{9}$ & $85.08 \times 10^{9}$ & $-4.7 \%$ & $18.31 \times 10^{9}$ & $85.08 \times 10^{9}$ & $364.7 \%$ \\
\hline
\end{tabular}

${ }^{\text {a }}$ Deviation $=100 \times($ observed - expected $) /$ expected .

\section{Results}

The gorilla and orangutan cerebella in our sample have similar sizes and cellular compositions, weighing $37.56 \mathrm{~g}$ and $35.06 \pm 4.34 \mathrm{~g}$ and holding 29.3 and $28.5 \pm$ 3.78 billion cells, respectively. The vast majority of these cells are identified by their nuclear morphology as granule cell neurons (fig. 1), which amount to 26.4 billion in the gorilla (90.1\% of all cells) and $26.3 \pm 2.47$ billion in the orangutan cerebellum ( $92.3 \%$ of all cells; these percentages are similar to those observed in the cerebellum of other primates [Herculano-Houzel et al., 2007; Gabi et al., 2010]). Purkinje cells amount to 9.79 million in the gorilla and $13.10 \pm 1.69$ million in the orangutan cerebellum, such that the granule cell/Purkinje cell ratio in these species is 2,697 and $1,912 \pm 435$, respectively.

The cellular composition of the cerebellum of these great apes departs from the expected for cerebellar mass from the primate scaling rules [Herculano-Houzel et al., 2007] by about $30-40 \%$, only slightly more than other primate cerebella examined previously, including human cerebellum. However, most of this discrepancy is probably due to the likely shrinkage of the tissues after over 10 years of fixation in paraformaldehyde, which would decrease structure mass without affecting the total number of cells. Indeed, the numbers of cells observed depart by $-24.7 \%$ from that expected for a gorilla cerebellum of $64.5 \mathrm{~g}$ [Sherwood et al., 2004] and by only 5.2\% from an orangutan cerebellum of $48.5 \mathrm{~g}$ [Semendeferi and Damasio, 2000]. In contrast, the gorilla and orangutan cerebella contain almost 5 times more cells than would be expected for rodent cerebella of similar size (table 2), which demonstrates how well the gorilla and orangutan cerebella conform to the cellular scaling rules that apply to other primates as opposed to the closely related mammalian order, rodents.

The addition of the gorilla, orangutan and human cerebella [from Azevedo et al., 2009] to the other primate cerebella analyzed previously [Herculano-Houzel et al., 2007] does not modify the power functions relating cerebellar mass and number of cells (fig. 2a) and neurons (fig. 2b), which have exponents close to unity with or without the addition of these 3 large-brained species. Controlling for phylogenetic relatedness in the dataset that includes orangutans, gorillas and humans changes the exponents very little, from 0.971 to 0.997 (fig. $2 \mathrm{a}, \mathrm{p}<0.0001$ ), and from 0.999 to 1.010 (fig. $2 \mathrm{~b}, \mathrm{p}<0.0001$ ). This stability strongly suggests that the cerebella of the gorilla and orangutan, like the human cerebellum, scale linearly in size with their numbers of cells, as other primate cerebella do.

To test whether the gorilla and orangutan cerebral cortices also conform to the primate cellular scaling rules, we used the number of cells found in their cerebella to predict the size of the cerebral cortex expected for primates, as well as for rodents, for the sake of comparison. Figure 3 shows that the number of cells in the cerebellum can be used to predict structure mass and numbers of neurons and non-neuronal cells in the cerebral cortex of different primate species with typically $20 \%$ accuracy. With 28.5 or 29.3 billion cells in the cerebellum, primate cerebral cortices (including the white matter) would be expected to weigh 394 or $406 \mathrm{~g}$, respectively. In contrast, with these numbers of cells in the cerebellum, cerebral cortices of rodent brains would be expected to weigh 2,242 and 


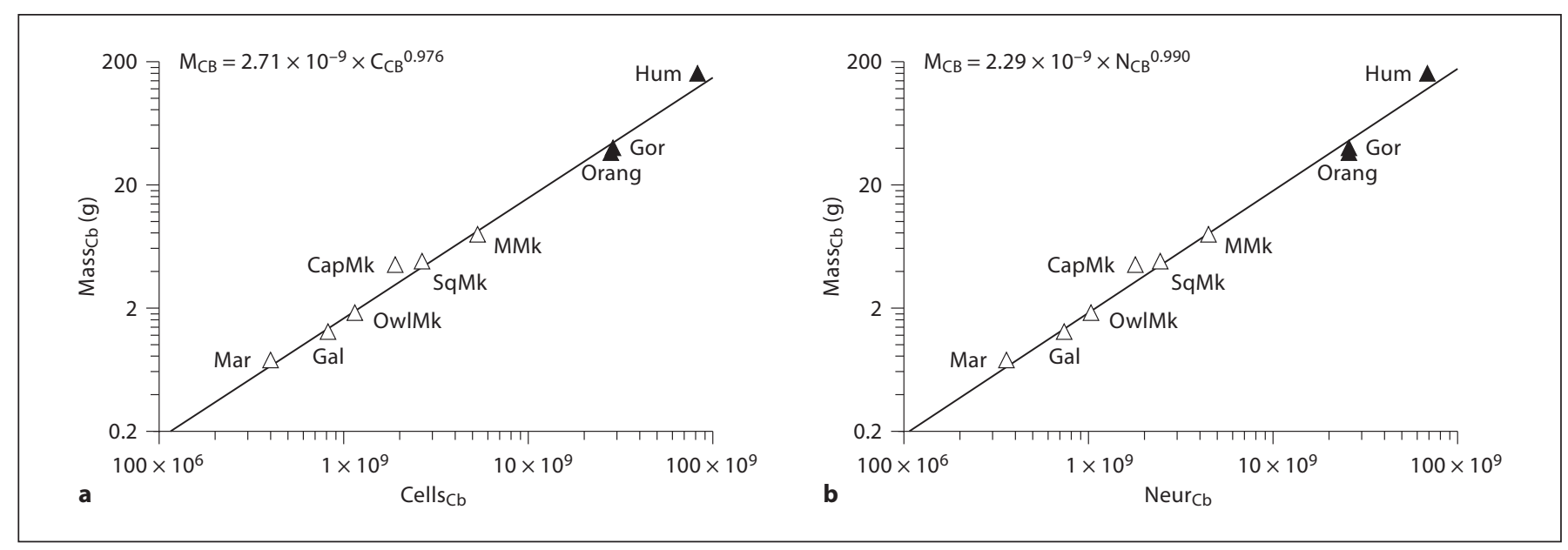

Fig. 2. Scaling of cerebellar mass as a function of the number of cerebellar cells (a) or cerebellar neurons (b). Plotted functions (indicated in the graphs) apply to the 6 primate species described previously [Herculano-Houzel et al., 2007]; notice that great apes and human cerebellar data fall close to the plotted line. Addition

of great apes and human data does not modify these functions significantly (which then become $\mathrm{M}_{\mathrm{CB}}=2.96 \times 10^{-9} \times \mathrm{C}_{\mathrm{CB}}{ }^{0.971}$ and $\mathrm{M}_{\mathrm{CB}}=1.86 \times 10^{-9} \times \mathrm{N}_{\mathrm{CB}}{ }^{0.999}$, respectively), and controlling for phylogenetic relatedness in the dataset changes these exponents only minimally, from 0.971 to 0.997 , and from 0.999 to 1.010 .

Fig. 3. Deviation of observed mass, number of neurons and number of non-neuronal cells in the cerebral cortex from the values expected from the total number of cells in the primate cerebellum according to the equations $\mathrm{M}_{\mathrm{CX}}=1.921 \times 10^{-9} \times \mathrm{C}_{\mathrm{CB}}{ }^{1.082}, \mathrm{~N}_{\mathrm{CX}}=$ $3.634 \times \mathrm{C}_{\mathrm{CB}}{ }^{0.898}$ and $\mathrm{NN}_{\mathrm{CX}}=0.069 \times \mathrm{C}_{\mathrm{CB}}{ }^{1.114}$ derived from data available for the 6 primate species shown in the left part of the plot [from Herculano-Houzel et al., 2007]. Bars indicate average deviation, 25th and 75th percentiles, and maximum and minimum deviations from the expected values. Bars for Pongo and Gorilla refer to cortical mass only.

2,335 g, respectively [Herculano-Houzel et al., 2006]. The values of 394 and $406 \mathrm{~g}$ expected for the orangutan and gorilla cerebral cortices based on the primate scaling rules vary by less than $10 \%$ from the actual weights of 415 and $377 \mathrm{~g}$ (including the white matter), respectively, described in the literature for these species [Semendeferi and Damasio, 2000], which strongly suggests that the gorilla and orangutan cerebral cortices, although not analyzed here, also conform to the primate cellular scaling rules.

Given the conformity of both cerebellum and cerebral cortex to the primate scaling rules, we next used the number of cells in the cerebellum of the gorilla and orangutan

to estimate the numbers of neuronal and other cells in the whole brain of these animals and their structures, using the human brain for comparison, applying the equations shown in table 3 (derived from data available for the same 6 primate species used in the other analyses [HerculanoHouzel et al., 2007]). From the number of cells that we found recently in the human cerebellum [Azevedo et al., 2009], the human brain is estimated to weigh $1,433 \mathrm{~g}$ and to hold 93 billion neurons, divided across the structures in a manner that closely matches the values we have observed using the isotropic fractionator (table 3). This similarity validates the approach of estimating primate brain 
Table 3. Equations determining the expected mass and numbers of cells in the whole brain, cerebral cortex, cerebellum and rest of brain from the total number of cells in the cerebellum

\begin{tabular}{|c|c|c|c|}
\hline & Mass & Number of neurons & Number of non-neurons \\
\hline $\begin{array}{l}\text { Whole brain } \\
\text { Cerebral cortex } \\
\text { Cerebellum } \\
\text { Rest of brain }\end{array}$ & $\begin{array}{l}\mathrm{M}_{\mathrm{BR}}=1.018 \times 10^{-8} \times \mathrm{C}_{\mathrm{CB}}{ }^{1.020} \\
\mathrm{M}_{\mathrm{CX}}=1.921 \times 10^{-9} \times \mathrm{C}_{\mathrm{CB}}{ }^{1.082} \\
\mathrm{M}_{\mathrm{CB}}=2.710 \times 10^{-9} \times \mathrm{C}_{\mathrm{CB}}{ }^{0.976} \\
\mathrm{M}_{\mathrm{ROB}}=2.277 \times 10^{-7} \times \mathrm{C}_{\mathrm{CB}} 0.789\end{array}$ & $\begin{array}{l}\mathrm{N}_{\mathrm{BR}}=3.219 \times \mathrm{C}_{\mathrm{CB}}^{0.957} \\
\mathrm{~N}_{\mathrm{CX}}=3.634 \times \mathrm{C}_{\mathrm{CB}}{ }^{0.898} \\
\mathrm{~N}_{\mathrm{CB}}=1.069 \times \mathrm{C}_{\mathrm{CB}}{ }^{0.991} \\
\mathrm{~N}_{\mathrm{ROB}}=133.178 \times \mathrm{C}_{\mathrm{CB}}{ }^{0.607}\end{array}$ & $\begin{array}{l}\mathrm{NN}_{\mathrm{BR}}=0.569 \times \mathrm{C}_{\mathrm{CB}}^{1.032} \\
\mathrm{NN}_{\mathrm{CX}}=0.069 \times \mathrm{C}_{\mathrm{CB}}^{1.114} \\
\mathrm{NN}_{\mathrm{CB}}=0.016 \times \mathrm{C}_{\mathrm{CB}}{ }^{1.089} \\
\mathrm{NN}_{\mathrm{ROB}}=35.175 \times \mathrm{C}_{\mathrm{CB}} 0.757\end{array}$ \\
\hline $\begin{array}{l}\text { Orangutan } \\
\text { Whole brain } \\
\text { Cerebral cortex } \\
\text { Cerebellum } \\
\text { Rest of brain }\end{array}$ & $\begin{array}{l}469.7 \text { g (observed: } 511.8 \mathrm{~g}^{\mathrm{a}} \text { ) } \\
\left.394.3 \mathrm{~g} \text { (observed: } 414.7 \mathrm{~g}^{\mathrm{a}}\right) \\
43.4 \mathrm{~g} \text { (observed: } 35.1 \mathrm{~g} \text { ) } \\
40.4 \mathrm{~g}\end{array}$ & $\begin{array}{l}32.6 \text { billion } \\
8.9 \text { billion } \\
24.5 \text { billion (observed: } 26.3 \text { ) } \\
0.3 \text { billion }\end{array}$ & $\begin{array}{l}35.0 \text { billion } \\
30.6 \text { billion } \\
3.9 \text { billion } \\
2.9 \text { billion }\end{array}$ \\
\hline $\begin{array}{l}\text { Gorilla } \\
\text { Whole brain } \\
\text { Cerebral cortex } \\
\text { Cerebellum } \\
\text { Rest of brain }\end{array}$ & $\begin{array}{l}483.0 \text { g (observed: } 486.1 \mathrm{~g}^{\mathrm{a}} \text { ) } \\
406.1 \mathrm{~g} \text { (observed: } 377.2 \mathrm{~g}^{\mathrm{a}} \text { ) } \\
44.5 \mathrm{~g} \text { (observed: } 37.6 \mathrm{~g} \text { ) } \\
41.3 \mathrm{~g}\end{array}$ & $\begin{array}{l}33.4 \text { billion } \\
9.1 \text { billion } \\
25.2 \text { billion (observed: } 26.4 \text { ) } \\
0.3 \text { billion }\end{array}$ & $\begin{array}{l}36.0 \text { billion } \\
31.5 \text { billion } \\
4.0 \text { billion } \\
2.9 \text { billion }\end{array}$ \\
\hline $\begin{array}{l}\text { Human } \\
\text { Whole brain } \\
\text { Cerebral cortex } \\
\text { Cerebellum } \\
\text { Rest of brain }\end{array}$ & $\begin{array}{r}\text { 1,432.8 g (observed: } 1,508.9 \mathrm{~g}^{\mathrm{b}} \text { ) } \\
1,287.1 \mathrm{~g} \text { (observed: } 1,232.9 \mathrm{~g}^{\mathrm{b}} \text { ) } \\
126.0 \mathrm{~g} \text { (observed: } 1,54.0 \mathrm{~g}^{\mathrm{b}} \text { ) } \\
95.7 \mathrm{~g} \text { (observed: } 1,17.7 \mathrm{~g}^{\mathrm{b}} \text { ) }\end{array}$ & $\begin{array}{l}92.8 \text { billion (observed: } 86.1 \text { ) } \\
23.7 \text { billion (observed: } 16.3 \text { ) } \\
72.5 \text { billion (observed: } 69.0 \text { ) } \\
0.6 \text { billion (observed: } 0.7 \text { ) }\end{array}$ & $\begin{array}{c}108.3 \text { billion (observed: } 84.6 \text { ) } \\
\text { 103.4 billion (observed: } 60.8 \text { ) } \\
12.8 \text { billion (observed: } 16.0 \text { ) } \\
6.6 \text { billion (observed: } 7.7 \text { ) }\end{array}$ \\
\hline
\end{tabular}

Equations calculated from data for 6 non-human primate species in Herculano-Houzel et al. [2007]. All values p < 0.01.

${ }^{a}$ Data from Semendeferi and Damasio [2000]. ${ }^{b}$ Data from Azevedo et al. [2009].

mass and cellular composition from the number of cells in the cerebellum.

With this approach, the orangutan brain is estimated to weigh $470 \mathrm{~g}$, which departs from the observed value of $512 \mathrm{~g}$ [Semendeferi and Damasio, 2000] by less than 10\%, and to be composed of 32 billion neurons ( 9 billion in cerebral cortex, 24 billion in the cerebellum and 0.3 billion in the remaining areas) and 35 billion non-neuronal cells, with a non-neuronal/neuronal ratio of about 1 , like other primates, humans included [Herculano-Houzel et al., 2007; Azevedo et al., 2009]. Similarly, the gorilla brain is estimated to weigh $483 \mathrm{~g}$, a value almost identical to the $486 \mathrm{~g}$ reported in the literature [Semendeferi and Damasio, 2000], and to contain 33 billion neurons and 36 nonneuronal cells (table 3). For the sake of comparison, a rodent brain with 28.5 or 29.3 billion cells in the cerebellum, like the orangutan or gorilla brains, would be expected to weight 2,827 or $2,937 \mathrm{~g}$; the discrepancy illustrates how well orangutan and gorilla brains seem to conform to the primate scaling rules.

While the gorilla and the orangutan brain size and numbers of cells seem to conform to the primate scaling rules, their body mass clearly deviates from the relationship found for other primate species. As shown in figure 4 , average body mass values for the primate species analyzed previously depart from the values expected from their numbers of cerebellar cells by at most $50 \%$, and human body mass closely matches the predicted $67 \mathrm{~kg}$. In contrast, the body mass range observed for the orangutan (30-50 kg for females, $50-90 \mathrm{~kg}$ for males) and the gorilla (70-140 kg for females, 75-275 kg for males [Nowak and Paradiso, 1983]) exceeds the expected values of 23.4 and $24.0 \mathrm{~kg}$ by at least 114 and $316 \%$, respectively.

\section{Hominin Taxa}

Since brain size has been found to increase linearly with number of neurons in non-human primates [HerculanoHouzel et al., 2007] as well as in humans [Azevedo et al., 2009], we postulate that numbers of neurons in hominin taxa must also relate to brain mass in a similar fashion, according to the same cellular scaling rules described previously and found here to apply to great apes as well.

By applying the scaling equations described in table 1 , we can predict the numbers of brain cells in pre-historic 


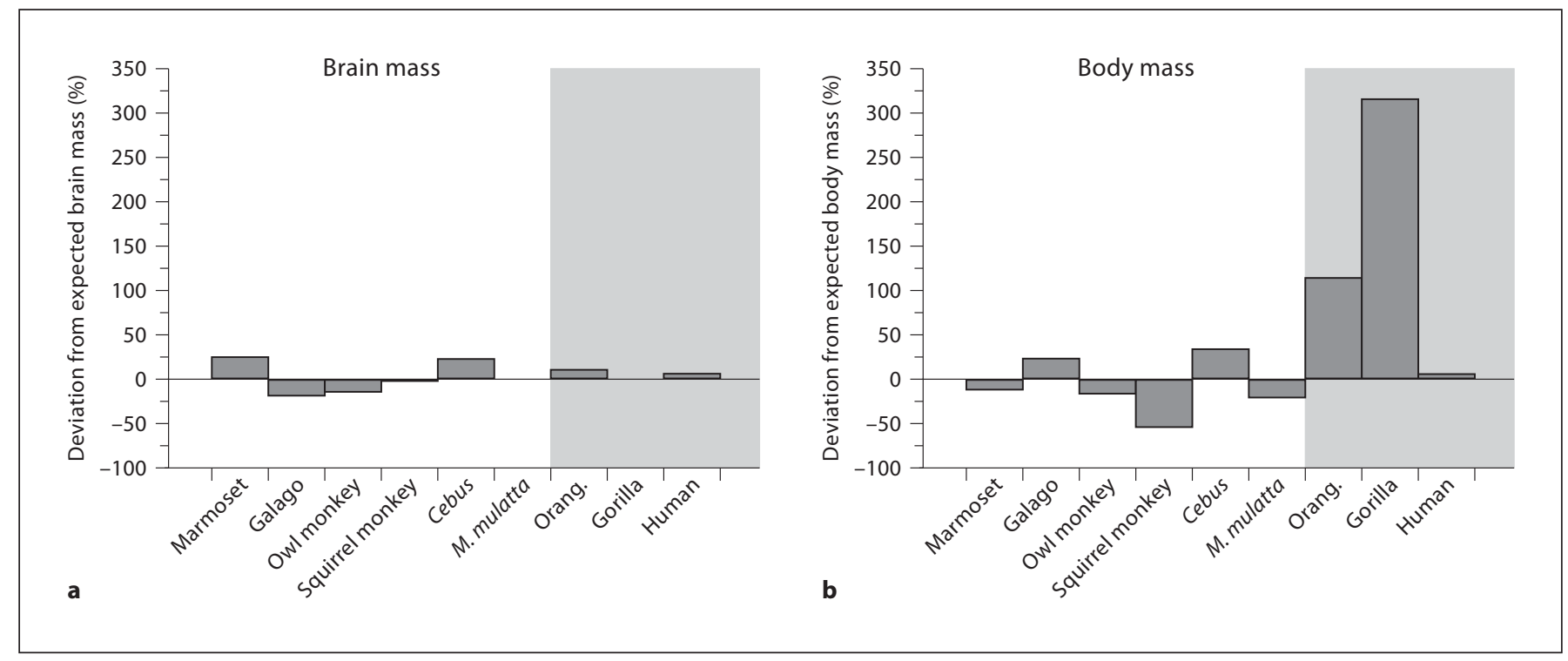

Fig. 4. Deviations of observed whole brain and body mass from the values expected from the total number of cells in the primate cerebellum according to the equations $\mathrm{M}_{\mathrm{BR}}=1.018 \times 10^{-8} \times$ $\mathrm{C}_{\mathrm{CB}}{ }^{1.020}$ and $\mathrm{M}_{\mathrm{BODY}}=2.258 \times 10^{-6} \times \mathrm{C}_{\mathrm{CB}}{ }^{0.958}$ derived from data available for the 6 primate species shown in the unshaded part of each plot [from Herculano-Houzel et al., 2007]. Notice that the predicted brain mass for the orangutan and gorilla match closely the observed values, while the body mass of these species vastly exceeds expectations. hominin taxa based on their brain mass (predicted from cranial capacity). While we find that predicted total numbers of neurons in the brain varied in Australopithecus and Paranthropus species within the same range as in great apes (predicted 27-35 billion neurons), a step to 5060 billion neurons is predicted to have occurred in Homo species from $H$. rudolfensis to $H$. antecessor. $H$. erectus is predicted to have had a brain of 62 billion neurons on average, with over $50 \%$ more neurons than $H$. habilis. Remarkably, $H$. heidelbergensis and $H$. neanderthalensis have predicted total numbers of neurons in the brain that fall within the range of variation found in modern $\mathrm{H}$. sapiens (76-90 billion neurons [Azevedo et al., 2009]).

To investigate how brain mass (and hence predicted numbers of neurons) in the brain, body size [from Frahm et al., 1982, and Marino, 1998] and relative brain size (as percentage of brain mass relative to body mass) varied in primate evolution, we plotted these variables for species belonging to different primate groups against time of divergence from the earliest common ancestor to each family [Purvis, 1995] (fig. 5 and 6). Note that this is not an attempt to reconstruct brain and body mass at different divergence points (as reported recently by Montgomery et al. [2010]), but rather a simple plot of known brain and body mass for each group against evolutionary time. This simple analysis suggests that relative body size increased in evolution until the divergence of the Cercopithecidae and Pongidae lineages, but then decreased progressively in the Homo lineage, to the point where current humans have the same relative body size found in groups that diverged earlier, such as Cercopithecidae and Cebidae (fig. 5a).

The trend towards decreasing then increasing relative brain size results from a trend towards increased brain mass over the last 30 million years (fig. 6b) [Montgomery et al., 2010] in contrast to a more liberal variation in body size, which is larger in Cercopithecidae and in Pongidae relative to the older species, but smaller in hominin than in most Pongidae (fig. 6a). Notice that the Pongidae and first hominin (Parapithecus, Australopithecus and the first Homo species) had similarly sized brains. Visual inspection of figure 6 thus corroborates the suggestion that brain and body mass evolution in the primate lineage have been relatively dissociated in the last 30 million years, as in other mammalian groups [Byrne, 1995; Finarelli and Flynn, 2009; Gonzalez-Voyer et al., 2009; Montgomery et al., 2010]. These results support the notion that, rather than humans having evolved too large a brain for their bodies, gorillas and orangutans evolved a large body independently of their brain size, as suggested by Shea 
Fig. 5. Time of divergence from earliest common ancestor for different primate lineages, in millions of years (Mya). a Relative brain mass for each group, expressed as percentage of body mass, is indicated on the right. Estimated numbers of neurons for great apes and hominin species are shown in billions. Based on Purvis [1995]. b Relative brain mass for individual species in each group plotted by time of divergence in millions of years (Mya).

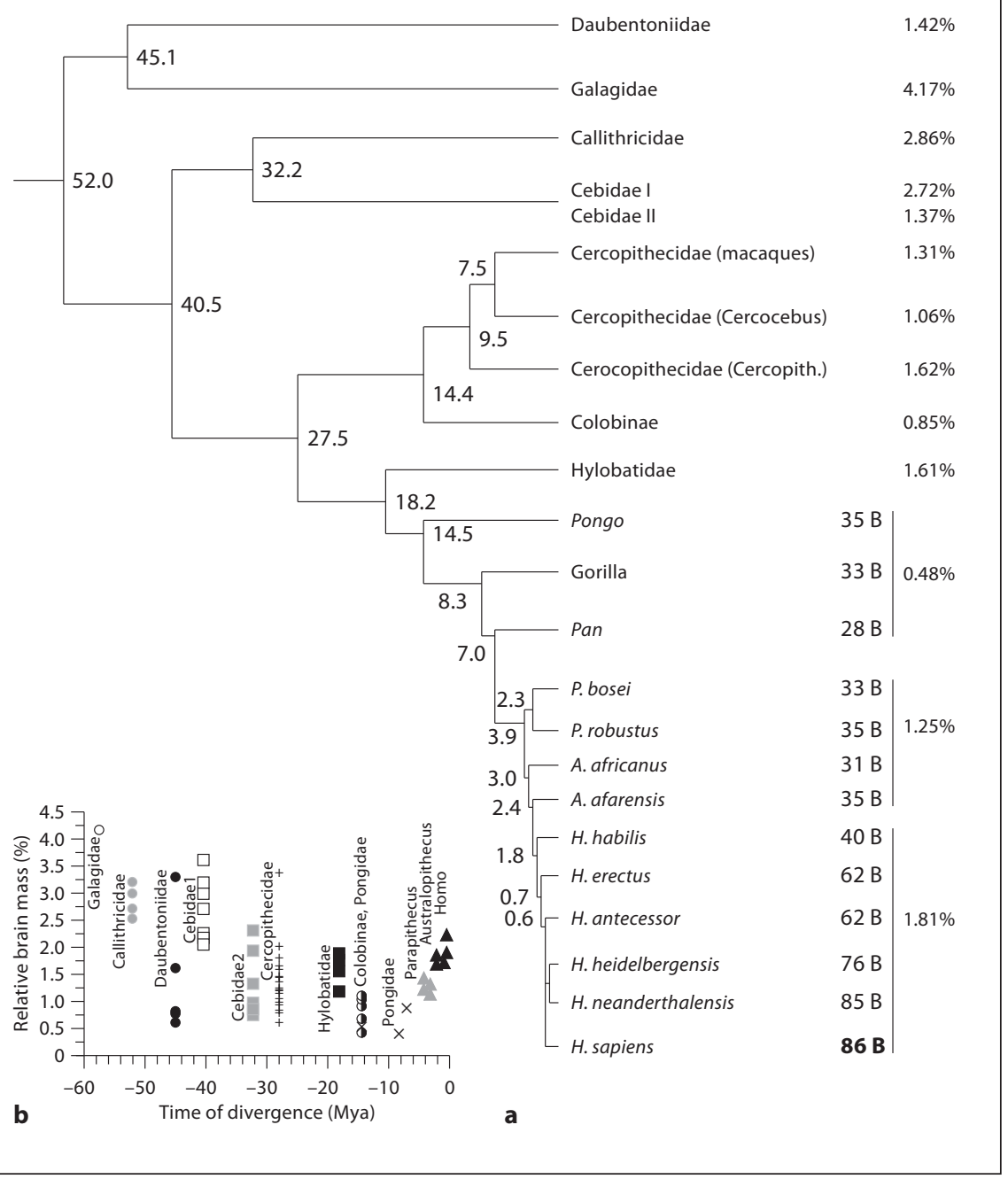

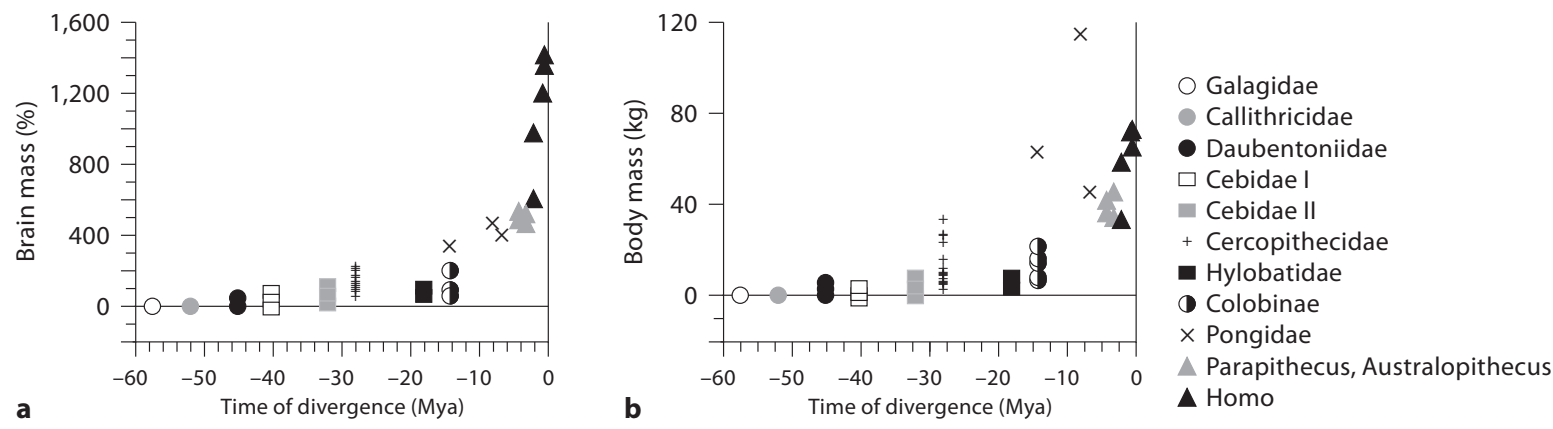

Fig. 6. Brain mass (a) and body mass (b) for each species in the different primate groups plotted by time of divergence (in millions of years, Mya) for each group from the latest common ancestor. 
Table 4. Predicted numbers of neurons in great ape and hominin brains

\begin{tabular}{|c|c|c|c|c|c|c|c|c|}
\hline Species & $\mathrm{M}_{\mathrm{BR}}$ & $\mathrm{M}_{\mathrm{CX}}$ & $\mathrm{M}_{\mathrm{CB}}$ & $\mathrm{M}_{\mathrm{RA}}$ & $\mathrm{N}_{\mathrm{CX}}$ & $\mathrm{N}_{\mathrm{CB}}$ & $\mathrm{N}_{\mathrm{RA}}$ & $\mathrm{N}_{\text {BRAIN }}$ \\
\hline Pan troglodytes & $406 \mathrm{~g}$ & $349 \mathrm{~g}$ & $36 \mathrm{~g}$ & $35 \mathrm{~g}$ & $8.0 \mathrm{~B}$ & $18.1 \mathrm{~B}$ & $0.3 \mathrm{~B}$ & $27.9 \mathrm{~B}$ \\
\hline Pongo pygmaeus & $512 \mathrm{~g}$ & $447 \mathrm{~g}$ & $44 \mathrm{~g}$ & $42 \mathrm{~g}$ & $9.8 \mathrm{~B}$ & $22.5 \mathrm{~B}$ & $0.3 \mathrm{~B}$ & $34.6 \mathrm{~B}$ \\
\hline Gorilla gorilla & $486 \mathrm{~g}$ & $422 \mathrm{~g}$ & $42 \mathrm{~g}$ & $40 \mathrm{~g}$ & $9.4 \mathrm{~B}$ & $21.4 \mathrm{~B}$ & $0.3 \mathrm{~B}$ & $33.0 \mathrm{~B}$ \\
\hline Sahelanthropus tchadensis & $363 \mathrm{~g}$ & $309 \mathrm{~g}$ & $32 \mathrm{~g}$ & $32 \mathrm{~g}$ & $7.2 \mathrm{~B}$ & $16.3 \mathrm{~B}$ & $0.2 \mathrm{~B}$ & $25.2 \mathrm{~B}$ \\
\hline Australopithecus afarensis & $514 \mathrm{~g}$ & $449 \mathrm{~g}$ & $44 \mathrm{~g}$ & $42 \mathrm{~g}$ & $9.8 \mathrm{~B}$ & $22.6 \mathrm{~B}$ & $0.3 \mathrm{~B}$ & $34.7 \mathrm{~B}$ \\
\hline Australopithecus africanus & $455 \mathrm{~g}$ & $394 \mathrm{~g}$ & $40 \mathrm{~g}$ & $38 \mathrm{~g}$ & $8.8 \mathrm{~B}$ & $20.1 \mathrm{~B}$ & $0.3 \mathrm{~B}$ & $31.0 \mathrm{~B}$ \\
\hline Australopithecus garhi & $446 \mathrm{~g}$ & $386 \mathrm{~g}$ & $39 \mathrm{~g}$ & $38 \mathrm{~g}$ & $8.7 \mathrm{~B}$ & $19.8 \mathrm{~B}$ & $0.3 \mathrm{~B}$ & $30.4 \mathrm{~B}$ \\
\hline Paranthropus aethiopicus & $407 \mathrm{~g}$ & $350 \mathrm{~g}$ & $36 \mathrm{~g}$ & $35 \mathrm{~g}$ & $8.0 \mathrm{~B}$ & $18.2 \mathrm{~B}$ & $0.3 \mathrm{~B}$ & $28.0 \mathrm{~B}$ \\
\hline Paranthropus boisei & $483 \mathrm{~g}$ & $420 \mathrm{~g}$ & $42 \mathrm{~g}$ & $40 \mathrm{~g}$ & $9.3 \mathrm{~B}$ & $21.3 \mathrm{~B}$ & $0.3 \mathrm{~B}$ & $32.8 \mathrm{~B}$ \\
\hline Paranthropus robustus & $525 \mathrm{~g}$ & $459 \mathrm{~g}$ & $45 \mathrm{~g}$ & $43 \mathrm{~g}$ & $10.0 \mathrm{~B}$ & $23.0 \mathrm{~B}$ & $0.3 \mathrm{~B}$ & $35.4 \mathrm{~B}$ \\
\hline Homo habilis & $599 \mathrm{~g}$ & $529 \mathrm{~g}$ & $51 \mathrm{~g}$ & $48 \mathrm{~g}$ & $11.3 \mathrm{~B}$ & $26.0 \mathrm{~B}$ & $0.4 \mathrm{~B}$ & $40.0 \mathrm{~B}$ \\
\hline Homo rudolfensis & $758 \mathrm{~g}$ & $680 \mathrm{~g}$ & $64 \mathrm{~g}$ & $57 \mathrm{~g}$ & $13.9 \mathrm{~B}$ & $32.3 \mathrm{~B}$ & $0.4 \mathrm{~B}$ & 49.7B \\
\hline Homo ergaster & $746 \mathrm{~g}$ & $668 \mathrm{~g}$ & $63 \mathrm{~g}$ & $56 \mathrm{~g}$ & $13.8 \mathrm{~B}$ & $31.8 \mathrm{~B}$ & $0.4 \mathrm{~B}$ & $49.0 \mathrm{~B}$ \\
\hline Homo erectus & $963 \mathrm{~g}$ & $878 \mathrm{~g}$ & $80 \mathrm{~g}$ & $68 \mathrm{~g}$ & $17.2 \mathrm{~B}$ & $40.3 \mathrm{~B}$ & $0.5 \mathrm{~B}$ & $62.0 \mathrm{~B}$ \\
\hline Homo antecessor & $972 \mathrm{~g}$ & $887 \mathrm{~g}$ & $81 \mathrm{~g}$ & $69 \mathrm{~g}$ & $17.4 \mathrm{~B}$ & $40.7 \mathrm{~B}$ & $0.5 \mathrm{~B}$ & $62.5 \mathrm{~B}$ \\
\hline Homo heidelbergensis & $1,200 \mathrm{~g}$ & $1,112 \mathrm{~g}$ & $98 \mathrm{~g}$ & $81 \mathrm{~g}$ & $21.0 \mathrm{~B}$ & $49.4 \mathrm{~B}$ & $0.5 \mathrm{~B}$ & $75.9 \mathrm{~B}$ \\
\hline Homo neanderthalensis & $1,353 \mathrm{~g}$ & $1,264 \mathrm{~g}$ & $110 \mathrm{~g}$ & $89 \mathrm{~g}$ & $23.3 \mathrm{~B}$ & $55.3 \mathrm{~B}$ & $0.6 \mathrm{~B}$ & $84.8 \mathrm{~B}$ \\
\hline Homo sapiens & $1,408 \mathrm{~g}$ & $1,319 \mathrm{~g}$ & $114 \mathrm{~g}$ & $92 \mathrm{~g}$ & $24.2 \mathrm{~B}$ & $57.3 \mathrm{~B}$ & $0.6 \mathrm{~B}$ & $88.0 \mathrm{~B}$ \\
\hline Homo floresiensis & $414 \mathrm{~g}$ & $356 \mathrm{~g}$ & $36 \mathrm{~g}$ & $36 \mathrm{~g}$ & $8.1 \mathrm{~B}$ & $18.4 \mathrm{~B}$ & $0.3 \mathrm{~B}$ & $28.4 \mathrm{~B}$ \\
\hline
\end{tabular}

All brain weights from de Sousa and Wood [2007]. Brain structure mass and number of neurons (in billion, B) predicted from the equations given in table 1, based on primate data published previously [Herculano-Houzel et al., 2007].

[1983], Riska and Atchley [1985], Byrne [1995] and Deacon [1997] - a trend that is not found in the chimpanzee and hominin lineage [Montgomery et al., 2010].

\section{Discussion}

The present analysis of the cellular composition of the orangutan and gorilla cerebellum shows that, in these great apes, this structure conforms to the cellular scaling rules that apply to other primate species, including humans. Further, the number of cells in the cerebellum is a good predictor of cortical and brain mass, which makes it seem likely that the entire brains of these great apes also conform to the scaling rules that apply to other primates. Thus, we infer that the brains of the gorilla and the orangutan are, like the human brain, built according to the same linear cellular scaling rules that apply to other primates. In this case, these cellular scaling rules can be used to estimate the number of neurons and other cells in the major divisions of the brains of now-extinct hominin species. We expect that our estimates of the numbers of neurons that composed the brains of hominin species will be illuminating in upcoming studies of the evolution of cognitive ca- pacity across species, as well as in comparative studies across large-brained taxa such as elephants, dolphins and whales, particularly in light of the proposition that absolute numbers of brain neurons, regardless of brain size, should be a limiting factor for cognition and thus a better predictor of cognitive ability than relative or absolute brain size or encephalization [Herculano-Houzel, 2009].

Interestingly, while the cellular scaling rules that apply to primate brains seem to have remained stable in hominin evolution, body size seems to have increased faster than brain size until the divergence of the Cercopithecidae and Pongidae lineages, but appears to have increased only little in the Homo lineage [Montgomery et al., 2010], to the point where current humans have the same relative brain size found in groups that diverged earlier in primate evolution, such as Cercopithecidae and Cebidae. This is best understood by considering brain and body mass separately: while brain mass tends to have increased in primate species over the last 30 million years, decreasing only in $H$. floresiensis [Montgomery et al., 2010], body mass underwent major increases in the Pongidae and Cercopithecidae lineages.

Such discrepancy between the evolution of brain and body mass is compatible with our previous observation 
that while the cellular scaling rules identified for a group of 6 primate species also apply to other samples of primates [Gabi et al., 2010], including humans [Azevedo et al., 2009], and hence probably to primates as a whole, the allometric rules relating body and brain size are very sensitive to the particular species sampled [Gabi et al., 2010]. This is also in line with the recent evidence that brain and body mass have been subject to separate selection pressures in primates [Montgomery et al., 2010] and that these often highly correlated traits can show differences in their patterns of evolution [Finarelli and Flynn, 2009; Gonzalez-Voyer et al., 2009]. Thus, brain size variation across species may be neither determined by body size nor together with it, but rather only loosely correlated with body size.

This notion is compatible with the view that body size can evolve either by change in the frequencies of genes that affect both brain and body size, generally during fetal and early postnatal growth, or by change only in the frequencies of genes that affect body size alone, and not brain size, generally in later growth [Riska and Atchley, 1985]. As a result, body size evolution occurring by changes in late growth will be accompanied by little parallel change in brain size. The correlation between adult brain and body mass therefore can vary between very low and very high, depending on the extent to which adult body mass is determined during early development alone or during later development as well.

Body mass, therefore, should not be considered as a variable determining, or contributing directly to, brain size - even though it is often correlated with brain size. In this sense, the finding of a particularly large adult body size in a species, such as the gorilla, does not imply that its brain should be correspondingly larger. Indeed, Shea [1983] notes that gorilla and chimpanzee neonates are very similar in size, and that body size divergence between these species has occurred by differences in rates of later postnatal growth, which occurs after the brain has achieved most of its mature size. This later postnatal growth is all the more evident in species with great sexual dimorphism, such as orangutans and gorillas - an issue that we cannot address here. However, the much larger sexual dimorphism of body size compared to brain size [Sherwood et al., 2004] in great apes also supports the notion that the determination and evolution of brain size can occasionally be dissociated from body size.

In light of the possibility of continued growth of the body after the brain has reached its adult size, we consider that the size of the human body, or of the body of any species, is not an accurate predictor of its brain mass, and should not be used as such, even though the calculation of relative brain mass or encephalization quotient may be useful for examining how brain and body masses relate across species. Along these lines, evolution of brain size should not be evaluated in light of adult body mass, but rather as a simultaneous process that is related to the evolution of adult body mass only to the extent that these 2 variables change together in early development. We propose, therefore, that the evolution of the hominin brain, and of the human brain in particular, involved 2 parallel but not necessarily related phenomena: an increase in brain size and number of neurons, obeying the same cellular scaling rules that apply to other primates, and a moderate increase in body size, compared to gorillas and orangutans, whose body size increased greatly compared to other primates who diverged earlier from the common ancestor.

Based on the results presented here, therefore, we consider that the notion that humans evolved too large a brain for their bodies is inappropriate, given that it is based on predictions made from body mass [Jerison, 1973; Marino, 1998]. Rather, we believe that human evolution is best accounted for by considering that, while the brain of all extant species as well as fossil hominins scaled in the same manner as a function of the number of neurons, great apes evolved a large body (diverging from the brain-body relationship that applies to earlier-diverging primates as well as for later-diverging humans) for reasons that may not be directly related to their brain size - a trend in evolution that was not pursued in the Homo lineage.

Growing a large body once adult brain size is achieved comes at a cost. While large animals require less energy per unit of body weight, they have considerably larger total metabolic requirements [Schmidt-Nielsen, 1984; Martin, 1990; Bonner, 2006]. Thus, large mammals need to eat more, and they cannot concentrate on rare, hard-tofind or catch foods [Conroy, 1990]. Indeed, great apes tend to eat more abundant but lower-quality plant foods. In exchange, as in many mammals, a larger size offers clear advantages in protection from predators, and more success in competition with others of the same species, or other species, for food and territory. In addition, a larger size in males typically reflects sexual selection as larger males are favored in male-male competition for mates [Plavcan and van Schaik, 1997a; Lindenfors and Tullberg, 1998]. Therefore, the unusually large and late-grown body size of the great apes appears to be a consequence of a focus on feeding on relatively abundant but less nutritious food under conditions of competition for food and 
territory as well as considerable male-male competition for mates.

Hominin evolution seems to have favored body sizes that do not require much late growth. As a result, modern humans have a body size that conforms to the brain-body relationship that applies to Old-World and New-World monkeys [Herculano-Houzel et al., 2007], and possibly to chimpanzees as well. While our species is mildly sexually dimorphic in body size, male-male competition does not seem to be highly dependent on body size. Notice that, until the Homo radiation, the first known hominin species had body masses in the same range as chimpanzees, and brain masses and predicted numbers of brain neurons in the same range as gorillas and orangutans. This suggests that hominin competition for resources was not strongly tied to body size. Rather, the addition of larger numbers of brain neurons, possibly first afforded in $H$. erectus by the ability to control the use of fire to cook and thus improve the caloric efficiency of foodstuffs [Wrangham, 2009] (although extractive foraging and food processing by other means were probably contributing factors as well), may have been a key factor in reproductive success in our lineage.

Given that cognitive abilities of non-human primates are directly correlated with absolute brain size [Deaner et al., 2007], and hence necessarily to the total number of neurons in the brain, it is interesting to consider that enlarged brain size, consequence of an increased number of neurons in the brain, may itself have contributed to shedding a dependence on body size for successful competition for resources and mates, besides contributing with larger cognitive abilities towards the success of our species [Herculano-Houzel, 2009]. In this regard, it is tempting to speculate on our prediction that the modern range of number of neurons observed in the human brain [Azevedo et al., 2009] was already found in H. heidelbergensis and $H$. neanderthalensis, raising the intriguing possibility that they had similar cognitive potential to our species. Compared to their societies, our outstanding accomplishments as individuals, as groups, and as a species, in this scenario, would be witnesses of the beneficial effects of cultural accumulation and transmission over the ages.

\section{Acknowledgments}

Thanks to Dr. Margarete Tigges of the Yekes Regional Research Center in Atlanta, Ga., USA, for providing the cerebella analyzed here, and to Ludmila Ribeiro for technical assistance. This study was funded by the CNPq, FAPERJ, INCT (MCT/ CNPq/FAPESP), and the James McDonnell Foundation (S.H.H.) and by NEI grant EY02686 (J.H.K.).

\section{References}

Azevedo FA, Carvalho LR, Grinberg LT, Farfel JM, Ferretti RE, Leite RE, Jacob Filho W, Lent R, Herculano-Houzel S (2009): Equal numbers of neuronal and nonneuronal cells make the human brain an isometrically scaled-up primate brain. J Comp Neurol 513: 532-541.

Bonner JT (2006): Why size matters: from bacteria to blue whales. Princeton, Princeton University Press.

Byrne RW (1995): The Thinking Ape: Evolution ary Origins of Intelligence. Oxford University Press, Oxford.

Conroy GC (1990): Primate Evolution. New York, WW Norton.

de Sousa A, Woods B (2007): The hominin fossil record and the emergence of the modern human central nervous system; in Kaas J (ed): Evolution of Nervous Systems: A Comprehensive Reference, vol 4. Oxford, Elsevier.

Deacon TW (1997): What makes the human brain different? Annu Rev Anthropol 26: 337-357.
Deaner RO, Isler K, Burkart J, van Shaick C (2007): Overall brain size, and not encephalization quotient, best predicts cognitive abilities across non-human primates. Brain Behav Evol 70:115-124.

Felsenstein J (1985): Phylogenies and the comparative method. Am Nat 125:1-15.

Finarelli JA, Flynn JJ (2009): Brain-size evolution and sociality in Carnivora. Proc Natl Acad Sci USA 106:9345-9349.

Frahm HD, Stephan H, Stephan M (1982): Comparison of brain structure volumes in Insectivora and Primates. I. Neocortex. J Hirnforsch 23:375-389.

Gabi M, Collins CE, Wong P, Kaas JH, Herculano-Houzel S (2010): Cellular scaling rules for the brain of an extended number of primate species. Brain Behav Evol 76:32-44.

Gazzaniga, M. (2008): Human: The Science Behind What Makes Us Unique. New York, Harper Collins.

Gonzalez-Voyer A, Winberg S, Kolm N (2009): Distinct evolutionary patterns of brain and body size during adaptive radiation. Evolution 63:2266-2274.
Herculano-Houzel S (2009): The human brain in numbers: a linearly scaled-up primate brain. Front Human Neurosci 3:31.

Herculano-Houzel S, Lent R (2005): Isotropic fractionator: a simple, rapid method for the quantification of total cell and neuron numbers in the brain. J Neurosci 25:2518-2521.

Herculano-Houzel S, Mota B, Lent R (2006): Cellular scaling rules for rodent brains. Proc Natl Acad Sci USA 103:12138-12143.

Herculano-Houzel S, Collins CE, Wong P, Kaas JH (2007): Cellular scaling rules for primate brains. Proc: Natl Acad Sci USA 104:35623567.

Jerison H (1973): Evolution of the brain and intelligence. New York, Academic Press.

Lindenfors P, Tullberg BS (1998): Phylogenetic analyses of primate size evolution: the consequences of sexual selection. Biol J Linn Soc 64:413-447.

Maddison WP, Maddison DR (2005): Mesquite: A modular system for evolutionary analysis, version 2.7. http://mesquite project.org 
Marino L (1998): A comparison of encephalization between odontocete cetaceans and anthropoid primates. Brain Behav Evol 51:230238.

Martin RP (1990): Primate origins and evolution: a phylogenetic reconstruction. Princeton, Princeton University Press.

-Montgomery SH, Capellini I, Barton RA, Mundy NI (2010): Reconstructing the ups and downs of primate brain evolution: implications for adaptive hypotheses and Homo floresiensis. BMC Biol 8:9.

Nowak RM, Paradiso JL (1983): Walker's Mammals of the World, 4th ed. Baltimore, John Hopkins University Press.

Pagel MD (1992): A method for the analysis of comparative data. J Theor Biol 156:431-442.

- Plavcan JM, van Schaik CP (1997a): Intrasexual competition and body weight dimorphism in anthropoid primates. Amer J Phys Anthro 103:37-68.
Plavcan JM, van Schaik CP (1997b): Interpreting hominid behavior on the basis of sexual dimorphism. J Human Evol 32:345-374.

Purvis A (1995): A composite estimate of primate phylogeny. Phil Trans R Soc Lond B 348:405-421.

Rilling JK (2006): Human and nonhuman primate brains: are they allometrically scaled versions of the same design? Evol Anthropol 15:65-77.

Riska B, Atchley WR (1985): Genetics of growth predict patterns of brain-size evolution. Science 229:668-671.

Schmidt-Nielsen K (1984): Scaling: Why Is Animal Size so important? Cambridge, Cambridge University Press.

Schoenemann PT (2004): Brain size scaling and body composition in mammals. Brain Behav Evol 63:47-60.
Semendeferi K, Damasio H (2000): The brain and its main anatomical subdivisions in living hominoids using magnetic resonance imaging. J Hum Evol 38:317-332.

Shea BT (1983): Size and diet in the evolution of African ape craniodental form. Int J Primatol 4:33.

Sherwood CC, Cranfield MR, Mehlman PT, Lilly AA, Garbe JAL, Whittier CA, Nutter FB, Rein TR, Bruner HJ, Holloway RL, Tang CY, Naidich TP, Delman BN, Steklis HD, Erwin JM, Hof PR (2004): Brain structure variation in great apes, with attention to the mountain gorilla (Gorilla beringei beringei). Am J Primatol 63:149-164.

Stephan H, Frahm H, Baron G (1981): New and revised data on volumes of brain structures in insectivores and primates. Folia Primatol 35:1-29.

Wrangham R (2009): Catching fire: how cooking made us human. New York, Basic Books. 